\title{
Bullying como violência sistemática que conduz à estigmatização nas escolas de futebol
}

\author{
Bullying as a systematic violence that leads to stigmatization in soccer schools
}

Bullying como violencia sistemática que conduce a la estigmatización en las escuelas de fútbol

\author{
Guilherme de Oliveira Gonçalves ${ }^{\mathrm{I}}$, Everton Luís Deiques ${ }^{\mathrm{II}}$, André Luis Xavier Peres Carlos ${ }^{\mathrm{III}}$ \\ Alberto Rosário Izidoro Júnior ${ }^{\mathrm{IV}}$
}

\begin{abstract}
Resumo
Milhares de crianças trilham o caminho da prática esportiva do futebol no Brasil. O bullying é um fenômeno presente no ambiente familiar, escolar e esportivo, inclusive em escolas esportivas de futebol, e que gera muitas consequências nocivas. A metodologia utilizada foi pesquisa bibliográfica, com base em periódicos digitais. Os principais alvos de bullying nas escolinhas de futebol são os alunos com dificuldades motoras, obesidade, ou com alguma deficiência e as meninas. Conclui-se que o futebol, o professor, pais e outras pessoas participantes do processo formativo devem estar atentos para evitar a ocorrência do fenômeno bullying, buscando através da educação e do esporte contribuir com o desenvolvimento de valores, como respeito, confiança, autoestima, cooperação, valorizando o trabalho em grupo, a prática saudável e a amizade.
\end{abstract}

Palavras-chave: Esportes; Ensino; Inclusão educacional

\begin{abstract}
Thousands of children walk the soccer path as a sports practice in Brazil. Bullying is a phenomenon present in the family, school and sports environment, including in soccer sports schools, and that generates many harmful consequences. The methodology used in this study was bibliographic research, based on digital journals. The main targets of bullying in the soccer schools are the students with motor difficulties, obesity or with some deficiency and also the girls. It is concluded that football, teacher, parents and other people that participate in the training process should be attentive to avoid the occurrence of the bullying phenomenon, seeking through education and sports to contribute to the development of values such as respect, confidence, self-cooperation, valuing the group work, the healthy practice and the friendship.
\end{abstract}

Keywords: Sport; Teaching; Educational Inclusion

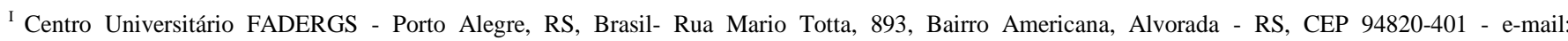
professorguilhermeg@gmail.com

II Federação Internacional de Educação Física - FIEP-RS - Porto Alegre, RS, Brasil - e-mail: everton@ deiques.com.br

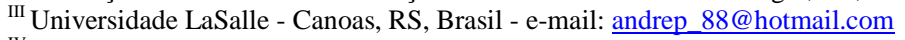

${ }^{\text {IV }}$ Centro Universitário FADERGS - Porto Alegre, RS, Brasil - e-mail: $\underline{\text { zzidorotkd@ hotmail.com }}$
} 


\section{Resúmen}

Miles de niños recorren el camino de la práctica deportiva del fútbol en Brasil. El bullying es un fenómeno presente en el ambiente familiar, escolar y deportivo, incluso en escuelas deportivas de fútbol, y que genera muchas consecuencias nocivas. La metodología utilizada fue la pesquisa bibliográfica, con base en periódicos digitales. Los principales centros de bullying en las escuelas de fútbol son los alumnos con dificultades motoras, obesidad, o con alguna discapacidad y las niñas. Se concluye que el fútbol, el profesor, padres y otras personas participantes del proceso formativo deben estar atentos para evitar la ocurrencia del fenómeno bullying, buscando, a través de la educación y del deporte, contribuir con el desarrollo de valores, como respeto, confianza, autoestima, cooperación, valorizando el trabajo grupo, la práctica saludable y la amistad.

Palavras clave: Deportes; Enseñanza; Inclusión educacional

\section{Introdução}

O bullying é um fenômeno com diversas causas e que gera muitas consequências nocivas como a estigmatização de alunos, que arcam com estigmas sociais que podem marcar tanto sua infância, adolescência e até mesmo a vida adulta. Pode-se observar que o bullying é capaz de conduzir a pessoa a um processo de estigmatização. Porém, é possível também perceber que a estigmatização já existente, ou seja, a criança estigmatizada passa a ser o alvo principal de bullying. Portanto, o bullying causa estigmatização e a estigmatização causa o bullying.

Este fenômeno social que acaba sendo visto inicialmente na escola por ser o segundo ambiente de socialização que temos em nossa cultura, excetuando-se a família que a ela é concedida a primeira e mais importante geratriz dos valores e princípios do ser humano (FURTADO e MORAES, 2010).

No Brasil devido a grande cultura do futebol, popularizada em todas as camadas sociais, a mídia e o marketing esportivo permitem a grande visibilidade desse esporte. A propagação de muitas escolinhas de futebol, que levam milhares de crianças a trilhar o caminho da prática esportiva desta modalidade, sendo muito comum também haver manifestação de bullying no ambiente esportivo.

Desta forma, o presente estudo tem como objetivo, através de uma visão de literatura, compreender como ocorre o bullying nas escolas de futebol, e encontrar estratégias para evitar e enfrentar este fenômeno.

\section{A prática do futebol e a ocorrência de bullying}

O esporte é um dos conteúdos desenvolvidos nas escolas, tanto no ensino fundamental como no médio, sendo que um dos esportes preferidos pela maioria dos meninos, e também por muitas meninas é o futebol. Com isso muitas escolas têm equipes esportivas dessa modalidade, participando de campeonatos entre as turmas, entre 
escolas, e olimpíadas escolares, onde tem diversos esportes disponíveis para competição, e muitas vezes a modalidade mais concorrida pelos participantes é o futebol.

Nas escolinhas de futebol é muito comum a procura dos pais tendo por objetivo colocar seus filhos para que eles tenham um habito saudável, em um ambiente que pode proporcionar aprendizado significativo na educação da criança ou adolescente. Com a crescente diminuição de espaços públicos e seguros para as práticas esportivas, locais particulares, e projetos sociais são alternativas para prática dessa modalidade. Para Scalon (2004) a criança procura iniciar uma prática esportiva, buscando principalmente, divertimento, alegria e prazer. Ela vai ao encontro de seus amigos e também no intuito de fazer novas amizades. Desenvolver aulas dinâmicas, com desafio a todos, torna agradável e motivam os alunos que chegam neste novo ambiente. O ensino lúdico também proporciona oportunidades para iniciação de uma forma descontraída. Existem escolinhas que já oferecem turmas para prática do futsal, de maneira lúdica, a partir dos três anos. Há diversos campeonatos com disputa de crianças já partir dos cinco anos.

Outro ponto que estimula a busca por uma prática regular de exercícios, é o aumento da obesidade infantil, que evidencia uma realidade onde em um mundo cada vez mais dinâmico, as pessoas têm pouco tempo disponível para o lazer e prática de exercício físico, e realização de alimentação saudável. Em alguns casos os pais buscam atividades físicas somente devido à indicação de médicos que indicam a necessidade de alimentação saudável e a prática de exercício físico para melhorar a saúde. Martines (2012) fala que os alunos do ensino fundamental, mesmo entre aqueles que têm obesidade, o futebol está entre os esportes preferidos, e que os mesmos entendem ser importante a prática de atividades físicas para a saúde. As meninas apesar de pensarem o mesmo, entendem que os meninos têm mais oportunidades para a prática de futebol do que elas.

A obesidade é comumente associada ao estigma da discriminação, pois no esporte de rendimento a preferência é sempre pelos mais rápidos, mais fortes e mais técnicos, quando se pratica esporte, mesmo que no ambiente infantil, privilegiando a competitividade, esse estigma transforma-se em um obstáculo. Deve-se diminuir o caráter competitivo, e a busca unicamente pela vitória, neste caso trabalha-se o esporte como veículo educacional, desenvolvendo a prática onde o valor de equipe sobrepõe-se ao esporte competição. Para Ortiz (2005) as atividades devem proporcionar uma participação ampla das crianças e adolescentes no processo de ensino-aprendizagem, sendo este papel importante como meio pedagógico. O ato de jogar deve ser utilizado como meio formativo, na infância e na adolescência. A atividade lúdica deve ser utilizada como um elemento metodológico, pois auxilia a criança em sua formação integral.

Na perspectiva da inclusão, o professor deve sempre buscar alternativas para que possa desenvolver um trabalho bem planejado no qual todos os praticantes da turma possam participar juntos e desenvolver-se. Para Montoan et tal (2006);

A educação inclusiva tem sido caracterizada como um "novo paradigma", que se constitui pelo apreço à diversidade como condição a ser valorizada, pois é benéfica a escolarização de todas as pessoas, pelo respeito aos diferentes ritmos de aprendizagem e pela preposição de outras práticas 
pedagógicas, o que exige ruptura com o instituído na sociedade e, consequentemente, nos sistemas de ensino.

Sabe-se que nossa sociedade, apesar dos debates frequentes sobre a inclusão e o respeito às diferenças, produz e muitas vezes reproduzem preconceitos que acabam criando estigmas sociais que prejudicam muitas pessoas, ora sem intensão, ora intencionalmente, sendo ato discriminatório e podendo levar a exclusão. Deve-se valorizar o esporte, como ferramenta educacional, possibilitando aqueles que poderiam ficar marginalizados, na perspectiva competitiva, possam ser também protagonista em uma proposta pedagógica, visto que o esporte agrega diversos valores, desenvolvendo ou seguindo princípios educacionais, como observa Bickel et al (2012):

Liderança, trabalho em equipe, respeito às regras, são alguns exemplos de valores que são vivenciados, muitas vezes indiretamente, quando há a intervenção de algum profissional de Educação Física, com a intenção de provocar a produção destes valores nos participantes da atividade física.

O processo de inclusão não é fácil, visto que exige análise da situação e dos envolvidos no processo, e buscar ações de como fazer com que eles compreendam o seu papel, e a necessidade de uma mudança, pois isso exige uma mudança de postura, pois é mais fácil para muitos não dar a devida atenção e ficar acomodados, passivos, deixando que os valores a ser desenvolvidos se percam em meio à comodidade. Para Lima (2010) atualmente fala-se muito em inclusão social, porém é importante o questionamento das condições dessa inclusão. Principalmente, se é possível incluir as pessoas no modelo social em que estamos inseridos. No modelo atual é muito difícil, é necessário primeiramente a transformação do modelo de sociedade para que se possam incluir as pessoas e assim estabelecer oportunidades de igualdade social.

O estigma envolve um processo social de duas partes, o indivíduo considerado "normal" e o "estigmatizado", no qual cada indivíduo participa de ambos em pelo menos algumas situações da vida. O processo de estigmatização pode ocorrer durante qualquer contato social, pois o normal e o estigmatizado são perspectivas geradas em situações sociais durante os contatos e que extrapolam esta relação para todo o grupo social. A tendência à categorização de pessoas, sendo que a rigidez tende a ser fonte inesgotável de preconceitos e visões estereotipadas das pessoas. Um estigma posto a um indivíduo prejudica sua reputação e prolongando-se talvez durante toda a vida do indivíduo (MONTE et al, 2009).

Os alunos com dificuldades motoras, obesidade, ou com alguma deficiência, podem tornar-se vulneráveis, principalmente em situações competitivas, onde eles podem ser estereotipados com o estigma de gordinho, ruim, lento, não sabe jogar, perna de pau e etc. É comum questionamentos de pais, ao professor sobre o porquê de determinados alunos estarem fazendo parte da equipe, sendo que eles atrapalham o desempenho dos colegas e de toda equipe. Situação essa comumente associada em casos de derrota, mais que passa totalmente despercebida aos olhos destas mesmas pessoas em caso de vitória. Nas escolas de futebol é necessário um olhar voltado para os aspectos sociais, à prática saudável de exercício e ao desenvolvimento, ou aprimoramento do repertório motor. Busca-se uma abordagem mais participativa, minimizando um pouco do peso excessivo das competições, que 
visam a participação somente dos melhores alunos, fazendo com que aqueles alunos com pouca habilidade não participarem de jogos, viagens e torneios, levando dessa forma a baixo-estima e a percepção por ele próprio de que não é capaz de participar da equipe, podendo dessa forma ser estigmatizado como "ruim", e com isso levar ao abandono esportivo. Com a cobrança e o fracasso nos resultados a criança sente-se responsabilizada, pelo seu desempenho, e por não corresponder às expectativas, ficando estigmatizado pelo seu baixo desempenho esportivo.

Para Guimarães (2013) essa perspectiva acelera a busca por resultados em competições esportivas, pois não se trabalha com a criança enquanto sujeito do processo, mas buscam-se objetivos em curto prazo, o que em diversos casos tem sido a causa do abandono precoce das crianças da prática esportiva. Uma das preocupações fundamentais de técnicos e professores que ministram aulas para crianças deveria estar relacionada com as características psíquicas, fisiológicas e motoras relacionadas a essa fase. Considera-se que a criança deve encontrar na prática do futebol, primeiramente a alegria e o entusiasmo pelo esporte e secundariamente os resultados, visto que o processo de ensino-aprendizagem de crianças no futebol deve-se buscar uma metodologia que proporcione a criança, o prazer e a motivação pelo jogar sem compromisso, sem pressões e cobranças que levam as crianças a frustração na prática desportiva.

Percebe-se então a necessidade de ter uma alternativa, para que esses alunos participem de atividades competitivas, como os colegas mais habilidosos, para que esses possam também desenvolver-se. Campeonatos internos, eventos esportivos que possibilitem a participação com outras escolas que tenham por filosofia incluir todos os alunos, até mesmo aqueles que têm baixo desempenho esportivo, é uma alternativa plausível.

Conversar com os alunos e pais, para que compreendam que a cobrança deve ser feita somente pelo profissional de educação Física, e não por outras pessoas, pois isso atrapalha o desempenho desse aluno que já é estigmatizado, podendo levar ao abandono do esporte. "Na verdade, de uma forma geral, são os adultos que socializam os jovens no sentido de que o sucesso passa por ser o 'melhor do que os outros' e não necessariamente por ser 'melhor do que antes' embora também possa suceder o contrario”. (FONSECA, 2004, p.282).

Diversas vezes os próprios pais criam estigmas em seus filhos, pelo seu desempenho e a forma como se portou em determinada partida, dessa forma, o praticante que já tem uma pressão interna para poder jogar bem, sofre pressão do ambiente, com a torcida ora incentivando, ora gritando e atrapalhando, e ainda tem a pressão dos pais que lhe cobram desempenho.

Na escola de futebol, com muita frequência os alunos participam de jogos amistosos, torneios e demais competições onde muitas crianças e adolescentes sofrem de ansiosidade, e sentem pressão (intrínseca e também da torcida) na busca pela vitória, levando alguns alunos mais habilidosos a estigmatizar aqueles que têm menos habilidade, questionando muitas vezes sua presença e importância no time, e enfatizando falhas técnicas que acontecem nos jogos. Entende-se necessária a conversa com todos os alunos no sentido de que os princípios de união, respeito, cordialidade, ajuda mútua devam ser mais importante para que todos possam participar juntos, enfatizando a importância do coletivo ao invés do individual. É necessário o profissional estar atento para essas 
situações que podem ocorrer tanto no treino, como em jogos contra outras escolas, atuando na orientação dos envolvidos, para que eles possam compreender o prejuízo que isso pode acarretar. Bickel et al (2012) fala que:

\footnotetext{
Os professores precisam entender que os jogos são uma forma de socializar os estudantes, que são momentos de diversão e, principalmente, de aprendizado. Caso isso não aconteça, corremos o risco de tornarmos estas competições em legítimos campos de batalha, ambientes de exclusão, de supervalorização da vitória, do vexame de uma derrota por não saber perder, da humilhação, assim por diante.
}

Nos casos das meninas os estigmas são na maioria das vezes associados com o fator de se creditar, erroneamente, que o futebol é um esporte para homem. Com o aumento da procura de meninas, mesmo com a prática do futebol feminino ser estigmatizado por muitas pessoas, percebe-se mobilização de muitas praticantes, e de professores que em suas escolas de futsal, apesar de não conseguir ter turmas somente de meninas, utilizam como estratégia, a inclusão da menina em uma turma compatível com seu desenvolvimento, junto com meninos, criando assim turmas mistas. Infelizmente esse preconceito pode-se evidenciar o estigma de alunos e pais, que tem dificuldade de aceitar uma aula, ou que meninos e meninas façam parte da mesma equipe, podendo-se escutar das arquibancadas expressões pejorativas como: - Futebol é coisa de homem. - Aquela menina vai estragar o time. Ou expressão que o indivíduo acredita ser um elogio, mas nada mais é que um estigma carregado de preconceito, como por exemplo: - Apesar de ser uma menina, ela joga bem.

Sendo o futebol uma modalidade historicamente e culturalmente masculina na sociedade brasileira, ele carrega o estigma da masculinidade, que fica evidente em brincadeiras pejorativas e comentários sobre a questão da homossexualidade das meninas que praticam o futsal, evidentemente recebido com bastante desagrado (STEVAUX e RODRIGUES, 2008). Além dos estigmas sofridos por jogadoras de futebol, referem-se relatos também das dificuldades de se conseguir apoios financeiros, devido preconceitos por parte de patrocinadores (STEVAUX e RODRIGUES 2008; KESSLER e CHITOLINA, 2009).

\section{Refletindo estratégias de combate ao bullying}

A estigmatização é um fato social enraizado em nossa sociedade, e é feito muitas vezes como se fosse algo natural, porém esse hábito mostra que algo que pode parecer corriqueiro e comum gera transtornos para quem é estigmatizado, tais como a exclusão de atividade sociais, distanciamento dos colegas, inibição de expor sua opinião e até mesmo sentimento de culpa por pensar que deveria ter características diferentes para não sofrer com atos pejorativos. O professor deve estar atento para poder perceber situação de estigmatização e poder atuar na inibição das mesmas, através do esclarecimento e diálogo para que quem estigmatiza possa compreender que isso gera consequências nocivas para o estigmatizado. A inclusão dos indivíduos que sofrem com estigma é um processo educacional muito debatido atualmente, mas que ainda está longe da compreensão de muitos professores.

Em estudo realizado em Itajaí - Santa Catarina, que avaliou a postura de professores quanto à inclusão, percebeu que muitos professores possuíam estigmas quando há alunos com deficiência física, e que não 
compreendiam estratégias de inclusão. Alguns pensavam que a aula não rendia quando tinham um aluno com deficiência, pois a aula tinha que ser voltada para esse aluno, e a aula era muito lenta e com pouca dinâmica. Em uma situação no recreio escolar os alunos maiores incluíram um aluno que gostaria de jogar futebol com os demais, mas que era de estatura muito baixa e tinha dificuldades de jogar, então eles sempre passavam a bola para este aluno antes de irem ao ataque, então ele acaba participando de quase todas jogadas da equipe, pois os jogadores da outra equipe davam um pouco de liberdade para ele poder receber o passe e produzir alguma jogada. Uma das professoras relatou que achou que esta não era a forma correta de jogar, pois esse é um jogo competitivo (SOUZA e PICH, 2013). Essa adaptação que os alunos realizaram permitiu a inclusão de um colega que conseguiu participar de atividades, e nem por isso o jogo deixou de ser atrativo aos seus participantes. Em escolas de futebol, a estratégia de passar a bola para um aluno que tenha dificuldade de jogar, e muitas vezes é estigmatizado por isso, e tenha tempo para poder receber e passar novamente a bola é uma estratégia que produz participação ativa deste aluno.

Em outra situação, em um treino de futsal, onde temos um aluno, com deficiência física, e ele tenha dificuldades de locomoção, e devido a sua dificuldade, fique complicado em colocar duas equipes equilibradas para competir, uma estratégia seria permitir que um dos times ficasse com um aluno a mais dentro de quadra, para que dessa forma as duas equipes ficassem com as mesmas possibilidades de jogar, e deste modo podendo todos jogar com as regras normais, porém com essa adaptação, ou se for necessário, para que o aluno com necessidade especial participe mais do jogo, colocar alguma regra como, por exemplo: quando esse aluno receber a bola os adversários só podem roubar a bola dele após dez segundos, que neste caso daria mais tempo para este aluno receber a bola e poder definir alguma jogada.

O professor deve refletir e buscar criar as estratégias que lhe permitam incluir alunos estigmatizados, pois como fala Souza e Pich (2013): "Ressaltamos que a inclusão não acontece pronta e que as ações didáticopedagógicas não estão descritas na literatura sob uma técnica padronizada que se possa seguir". Para Rechineli et al (2008) no presente os esforços para inclusão estão criando novas possibilidades, e no futuro, que se espera ser próximo, deve-se refletir sobre os corpos diferentes, analisar a partir da motricidade humana, respeitar em sua complexidade e sua totalidade no que pensam, sentem, aprendem, para que tenham a oportunidade de viverem, buscarem e se superarem, transcendendo a cada oportunidade vivida.

Para Guimarães et al (2001) é necessário que o professor assuma seu papel, colaborando com objetividade, o que não o impede de ser flexível, no processo de formação de valores e atitudes para que as crianças adquiram uma moral cidadã, e o indivíduo possa expressar seus valores através de atitudes positivas. Silva e Ferreira (2001) falam que os exercícios físicos representam papel importante no desenvolvimento global do indivíduo, pois seu desenvolvimento físico, mental e emocional e sua adaptação social dependem, em grande parte, das possibilidades que ele adquire de mover-se e de descobrir-se, sendo assim deve-se facilitar e adequar atividades para o indivíduo, oferecendo experiências que vão resultar num grande auxiliar de seu desenvolvimento. 


\section{Considerações Finais}

Para que possamos reduzir o bullying, devemos refletir constantemente estratégias de inclusão e integração, sendo que as ideias muitas vezes acontecem com base no estudo deste aluno, e na verificação de quais necessidades ele tem para que possa participar e ser incluso nas tarefas propostas, sempre atentas para esclarecer que o rendimento esportivo, e o desempenho motor esperado devem estar associados com aquilo que ele possa produzir. Valorizar o esforço, a participação, para que todos os colegas participem juntos é fator fundamental para o ensino-aprendizagem.

Os alunos com deficiência sofrem com estigmas e discriminações em diversos ambientes, sendo inferiorizados, subestimados e estigmatizados pela sociedade. Cabe ao professor a tarefa de criar oportunidade tangível para sua participação.

Pode-se concluir que mais pesquisas sobre o bullying e suas diversas manifestações, devem ser realizadas para que possamos compreender melhor esta lacuna, porém contamos que o futebol, esporte com tanta abrangência nacional, deve ser utilizado como veículo educacional, contribuindo no processo de formação, transmissão de valores, como respeito, cordialidade, confiança, autoestima, cooperação, tirando um pouco do caráter competitivo, valorizando o trabalho em grupo, a prática saudável e a amizade.

\section{Referências}

BICKEL, Éderson Alexandro. Esporte e sociedade: a construção de valores na prática esportiva em projetos sociais. Lecturas: Educación Física y Deportes. Buenos Aires, ano 17, n. 171, agosto. 2012.

FONSECA, António Manuel. O abandono das prátcas desportivas: aspectos psicológicos. In: GAYA, Adroaldo e colab. Desporto para crianças e jovens: razões e finalidades. Porto Alegre: Editora da UFRGS, 2004.

GUIMARÃES, Rodrigo Santos. Aspectos fundamentais no ensino do futebol para crianças: considerações iniciais. Lecturas: Educación Física y Deportes. Buenos Aires, ano 18, n. 187, dezembro de 2013.

GUIMARÃES, Ana Archangelo. Educação Física Escolar: atitudes e valores. Motriz, vol. 7, n 1, p. 17-22, jan./jun. 2001.

KESSLER, Claudia; ZANINI, Maria Catarina Chitolina. Contar ou não contar? As narrativas de jogadoras de Futebol de Santa Maria - RS. Mouseiun, v. 3, n 8, jul./dez. 2009.

LIMA, Liliane Nobre. Lazer, violência e estigma: estudos dos jovens do Vila do Ipê. 2010. 108f. Dissertação (Curso de Mestrado em Ciências) - Universidade Federal de Pelotas. Pelotas, 2010.

MARTÍNEZ, David Cuadra. Representación social de deporte y educación física en estudiantes con obesidad. Revista Latinoamericana de Ciencias Sociales, Niñez y Juventud, v. 10 (2), p. 983-1001. 2012.

MONTE, Naira Bacarreli. Ética, estigma e discriminação de grupos. Lecturas: Educación Física y Deportes. Buenos Aires, ano 14, n. 132, maio. 2009.

MONTOAN, Maria Tereza Eglér et al. Inclusão escolar: pontos e contrapontos. São Paulo: Summus, 2006. 
ORTIZ, Paredes Jesús. Aproximação teórica à realidade do jogo. In: Murcia, Juan Antonio Moreno e colab. Aprendizagem através do jogo. Porto Alegre: Artmed, 2005.

RECHINELI, Andréa; PORTO, Eline Tereza Rozante; MOREIRA, Wagner Wey. Corpos deficientes, eficientes e diferentes: uma visão a partir da educação física. Rev. bras. educ. espec. 2008, vol. 14, n.2, p. 293-310.

SCALON, Roberto Mário et al. Motivação no esporte. In: SCALON, Roberto Mário (org). A psicologia do esporte e a criança. Porto Alegre: EDIPUCRS, 2004.

SILVA, da Diorges Ricardo; FERREIRA, Juliana Saraiva. Intervenções na Educação Física em Crianças com Síndrome de Down. Journal of Physical Education. Maringá, v. 12, n. 1, p. 69-76. 2001.

SOUZA, de Gisele Cristina; PICH, Santiago. A reorientação da ação pedagógica na Educação Física sob a perspectiva da inclusão: a pesquisa-ação como caminho. Movimento. Porto Alegre, v. 19, n. 03, p. 149-169, jul/set. 2013.

STEVAUX, Ricardo Peixoto; RODRIGUES, Cae. As questões de gênero no futsal feminino. Disponível em: http://www.pucpr.br/eventos/educere/educere2008/anais/pdf/771_759.pdf

Acesso em: 24 fev. 2015.

\section{Como citar este artigo}

GONÇALVES, Guilherme de Oliveira; DEIQUES, Everton Luís; PERES, André Luis Xavier; IZIDORO JÚNIOR, Carlos Alberto Rosário. Bullying como violência sistemática que conduz à estigmatização nas escolas de futebol. Revista Kinesis, Santa Maria, v. 37, p. 01-10, 2019. 